
Pathophysiology of Haemostasis and Thrombosis

Received: April 17, 2002

Accepted in revised form: J une 18, 2002

\title{
Low Molecular Weight Heparin for the Prevention of Deep Venous Thrombosis: A Suitable Monitoring in Elderly Patients?
}

\author{
Isabelle Mahéa Ludovic Drouet ${ }^{\mathrm{b}}$ Olivier Chassany ${ }^{\mathrm{a}} \quad$ Anne-Sophie Grenard ${ }^{\mathrm{a}}$ \\ Charles Caulina J ean-François Bergmanna ${ }^{a}$ \\ aService Médecine A, et ${ }^{b}$ Laboratoire d'Hématologie Biologique, Hôpital Lariboisière, Paris, France
}

\section{Key Words}

Low molecular weight heparin . Deep vein thrombosis . Elderly · Anti-Xa activity

\begin{abstract}
Monitoring of anti-Xa activity ( $\mathrm{aXa}$ ) levels is not routinely required in patients receiving enoxaparine at prophylactic dosages, since aXa is supposed to stay below the manufacturer's recommended range in patients treated for venous thrombosis $(0.5-1 \mathrm{lU} / \mathrm{ml})$. In order to $\mathrm{aXa}$ in elderly subjects receiving prophylactic enoxaparin, 68 consecutive patients (mean age $82.5 \pm 10.7$ years) hospitalized in a medical department receiving 4,000 IU enoxaparin daily subcutaneously for the prevention of venous thromboembolic disease were studied. After the first injection of enoxaparin, the aXa of $57.4 \%$ patients was superior to $0.5 \mathrm{IU} / \mathrm{ml}$ while $69.4 \%$ had an aXa higher than 0.5 after $8.4 \pm 1.2$ days. A negative relationship between aXa and body weight and a trend towards a positive correlation between $\mathrm{aXa}$ and age but not with creatinine clearance were noted. Our findings question the opportunity to monitor aXa in elderly patients receiving 4,000 IU enoxaparin as antithrombotic prophylaxis. Copyright $\odot 2002$ S. Karger AG, Basel
\end{abstract}

\section{Introduction}

Low molecular weight heparins (LMWH) are widely used because of the recent marked expansion of the indications and the more convenient use than unfractioned heparin. Enoxaparin 4,000 IU subcutaneously is recommended for the prophylaxis of deep vein thrombosis (DVT) in orthopedic surgical patients [1]. It is also recommended in medical high risk since the results of the MEDENOX trial, a placebo-controlled double-blind randomized trial that showed that enoxaparin 4,000 IU significantly reduced the incidence of thromboembolic events and phlebographic DVT in recently hospitalized medical patients [2]. Following the publication of several reports and surveys, the bleeding risk of prophylactic LMWH is now recognized [1, 3, 4]. Age has been identified as a predisposing factor of heparin-related bleeding $[5,6]$.

Anti-Xa activity (aXa) assays are the most accurate method of monitoring anticoagulant response to LMWH therapy [1]. Associations between aXa levels and antithrombotic activity have been reported, but not substantiated in all studies [7-9]. Monitoring of aXa levels is not routinely required for patients receiving LMWH therapy at prophylactic dosages since aXa is supposed to stay below the manufacturer's recommended range (0.5-1 IU/ $\mathrm{ml}$ ) generated by enoxaparin delivered at the dose required to treat a patient presenting with venous thrombosis [1].

\begin{tabular}{ll}
\hline KARGER & ( ) 2002 S. Karger AG, Basel \\
Fax +41613061234 & 1424-8832/02/0323-0134\$18.50/0 \\
$\begin{array}{l}\text { E-Mail karger@karger.ch } \\
\text { www.karger.com }\end{array}$ & $\begin{array}{l}\text { Accessible online at: } \\
\text { www.karger.com/journals/pht }\end{array}$
\end{tabular}

Dr. Isabelle Mahé

Service Médecine A, Hôpital Lariboisière

2 , rue Ambroise-Paré

F-75010 Paris (France)

Tel. +33 1499563 42, Fax +331499584 46, E-Mail isabelle.mahe@lrb.ap-hop-paris.fr 
In medical situations, the only validated efficient dose of enoxaparin is 4,000 IU, but medical patients are often old with various risk factors for hemorrhage. The present study was designed to assess the characteristics of the plasma aXa in elderly hospitalized subjects receiving enoxaparin by subcutaneous injection at the 4,000 IU dose recommended for the prophylaxis of DVT.

\section{Patients and Methods}

Sixty-eight consecutive patients hospitalized in our Department of Internal Medicine (Lariboisière Hospital, Paris, France) and requiring 4,000 IU enoxaparin daily subcutaneously for the prevention of DVT were included after informed consent. The prescription was in accordance with the approved indication of the drug. Baseline clinical and biological characteristics (creatinine clearance was calculated using the Cockcroft formula), bleeding risk factors, body weight, concomitant therapies were recorded.

Blood samples for the determination of aXa were collected at peak level (4 $\mathrm{h}$ after the injection of enoxaparin) [1] and analysed by the same laboratory. aXa was determined using the Stachrom-heparin $^{\mathrm{TM}}$ kit fitted to an automated reader (STA) and calibration curves obtained using Hepanorm HBPM (Diagnostica Stago, Asnières, France). This system is submitted to quality control and regularly checked by regional and national quality control.

aXa was measured in all patients at the beginning of the treatment (day 1 or 2) and, in subjects who were still receiving enoxaparin, after 1 week of treatment. Statistical analysis was performed using analysis of variance. A p value below 0.05 was considered significant.

The manufacturer's recommended range of aXa for patients on exoxaparin for thrombosis is $0.5-1 \mathrm{IU} / \mathrm{ml}$. We hypothesized that to observe a significant proportion of patients $(30 \%)$ on this regimen with aXa levels higher than $0.5 \mathrm{IU} / \mathrm{ml}, 60$ subjects would be necessary.

\section{Results}

Sixty-eight patients participated in the study (mean age $82.5 \pm 10.7$ years, mean body weight $59.6 \pm 13.3 \mathrm{~kg}$, mean creatinine clearance $95.7 \pm 57.5 \mathrm{ml} / \mathrm{min}$ ). The first aXa measurement was performed $4 \mathrm{~h}$ after the first or the second injection of enoxaparin; the mean duration of enoxaparin therapy was $1.5 \pm 0.9$ days. Mean aXa was $0.52 \pm 0.20 \mathrm{IU} / \mathrm{ml}$. The percentage of patients with aXa greater than $0.5 \mathrm{IU} / \mathrm{ml}$ was $57.4 \%$ while 2 patients had an aXa superior to $1 \mathrm{IU} / \mathrm{ml}$. The individual values of aXa are given in figure 1 and 2.

The second aXa measurement was performed in 36 patients after a mean duration of enoxaparin therapy of $8.4 \pm 1.2$ days. Mean aXa was $0.61 \pm 0.18 \mathrm{IU} / \mathrm{ml}$. The proportion of patients with aXa greater than $0.5 \mathrm{IU} / \mathrm{ml}$ was $69.4 \%$ and aXa was above $1 \mathrm{IU} / \mathrm{ml}$ in 1 patient. Thirty-two patients had only 1 aXa measurement for the fol-
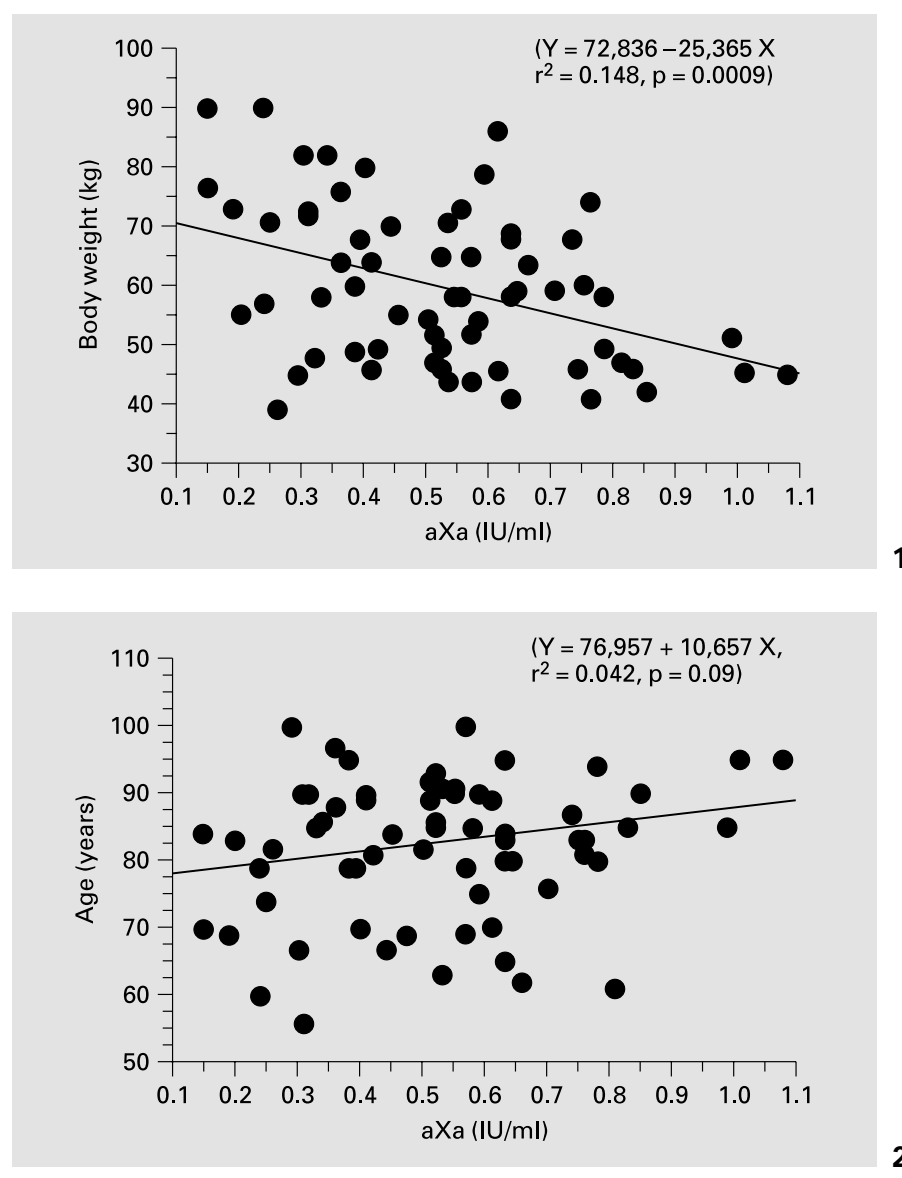

Fig. 1. Correlation between aXa and body weight.

Fig. 2. Correlation between aXa and age.

lowing reasons: change in the enoxaparin dosage $(n=8)$, discontinuation of the therapy $(\mathrm{n}=20)$, death $(\mathrm{n}=2)$, hemorrhagic event $(n=2)$.

A negative relationship between aXa and body weight $(p=0.0009)$ (fig. 1) and a trend towards a positive correlation between aXa and age $(p=0.09)$ were noted (fig. 2$)$, but not with the corrected creatinine clearance $(p=$ $0.20)$.

\section{Discussion}

The main finding of our study in an elderly population is that soon after the initiation of enoxaparin $(1.5 \pm 0.9$ days) at a prophylactic dosage (4,000 IU), peak aXa was higher than $0.5 \mathrm{IU} / \mathrm{ml}$ in nearly $60 \%$ of the patients (and $1 \mathrm{IU} / \mathrm{ml}$ in nearly $3 \%$ of patients). Several factors might contribute to explain these high aXa levels: lower body weight, renal dysfunction, age [3, 4]. These results are not 
in accordance with the aXa measurements performed in a subset of patients included in the MEDENOX trial ( $\mathrm{n}=$ 68): mean aXa at the end of the treatment (day $10 \pm 4$ days) in the enoxaparin 4,000 IU group was $0.41 \mathrm{IU} / \mathrm{ml}$ with no patient with aXa above $0.5 \mathrm{IU} / \mathrm{ml}[10]$.

As other authors reporting on LMWH at prophylactic dosages, we found that aXa might inversely correlate with body weight [11-13]. Although a physiological reduction in renal function related to aging is reported to induce accumulation after repeated administration of LMWH [12], no correlation between aXa and creatinine clearance could be established in our study as in the MEDENOX trial. This may be due to the fact that the rate of accumulation remains moderate in elderly subjects who have normal renal function for their age and is believed to have no clinical relevance [14].

The age of patients receiving LMWH might be important to consider because it is associated with an increased hemorrhagic risk [5,6]. Some authors reported a tendency to accumulate aXa in elderly subjects $[14,15]$; we observed a tendency to a correlation between aXa and age, while no correlation could be established in a subset of patients included in the MEDENOX trial. This might be due to the different characteristics of the patients included in the studies: both were medical patients who were going to stay in the hospital for at least 6 days, but the age was quite different $(74.1 \pm 10.6$ in the MEDENOX trial vs. $82.5 \pm 10.7$ years in our study). Put together this suggests that higher aXa levels might occur with increasing age.

Our findings suggest that the modalities of an optimal prophylactic treatment for thromboembolism in elderly patients may have to be revised. In the MEDENOX study, 4,000 IU was the only efficient dosage of enoxaparin for the prevention of DVT [2] while inducing a dose-dependent increase in aXa independently of other factors [10]. Our study performed in older patients shows that there is a wide interindividual variability of aXa in patients receiving enoxaparin 4,000 IU for 2 days. The fact is that in a substantial subset of patients (more than 60\%) aXa reaches the range which is usually recommended if the patient is receiving enoxaparin to treat a DVT; these patients might be at increased hemorrhagic risk. On the other hand, reducing the dose of enoxaparin in elderly patient might reduce the therapeutic benefit observed.

Older patients are at increased risk for both thromboembolic and hemorrhagic events. Although it is currently not recommended to monitor aXa in patients receiving $\mathrm{LMWH}$ for the prevention of DVT, our results suggest that aXa should indeed be monitored in elderly subjects to avoid overdose.

\section{References}

1 Hirsh J, Warkentin TE, Shaughnessy SG, Anand SS, Halperin JL, Raschke R, Granger C, Ohman EM, Dalen JE: Heparin and low-molecular-weight heparin: Mechanisms of action, pharmacokinetics, dosing, monitoring, efficacy, and safety. Chest 2001;119:64S-94S.

2 Samama MM, Thomas AT, Darmon JY, et al: A comparison of enoxaparin with placebo for the prevention of venous thromboembolism in acutely ill medical patients. N Engl J Med 1999;341:793-800.

3 Shaieb MD, Watson BN, Aktinson RE: Bleeding complications with enoxaparin for deep venous thrombosis prophylaxis. J Arthroplasty 1999, 14:432-438

4 Stern SH, Wixson RL, O'Connor D: Evaluation of the safety and efficacy of enoxaparin and warfarin for prevention of deep venous thrombosis after total knee arthroplasty. J Arthroplasty 2000;15:153-158.

5 Landefeld CS: Identification and preliminary validation of predictors of major bleeding in hospitalised patients starting anticoagulant therapy. Am J Med 1987;82:703-713.
6 Campbell NR, Hull RD, Brant R, Hogan DB, Pineo GF: Aging and heparin related bleeding. Arch Intern Med 1996;156:857-860.

7 Boneu B, de Moerloose P: How and when to monitor a patient treated with low molecular weight heparin. Semin Thromb Hemost 2001; 27:519-522.

8 Ockelford P, Carter CJ, Mitchell L, Hirsh J: Discordance between the anti-Xa activity and the antithrombotic activity of an ultra low molecular weight heparin fraction. Thromb Res 1982;28:401-409.

9 Troy S, Fruncillo R, Ozawa T: Absolute and comparative subcutaneous bioavailability of ardeparin sodium, a low molecular weight heparin. Thromb Haemost 1997;78:871-875.

10 Bara L, Boutitie F, Samama MM, Cohen AT, Combe S, Desjardins L, Eldor A, Janbon C, Leizorovicz A, Olsson CG, Turpie AGG: Correlation of plasma coagulation parameters with treatment, patient characteristics and outcome in the MEDENOX trial (abstract P2306). Thromb Haemost 2001 (suppl).
11 Collignon F, Frydman A, Caplain H: Comparison of pharmacokinetic profiles of $3 \mathrm{LMWH}$ administered in healthy volunteers. Thromb Haemost 1995;73:630-640.

12 Vitoux JF, Aiach M, Roncato M, Fiessinger JN: Should thromboprophylactic dosage of low molecular weight heparin be adapted to patient's weight? Thromb Haemost 1988;59:120.

13 Planes A, Samama MM, Lensing AW, et al: Prevention of deep venous thrombosis after hip replacement-comparison between the low molecular weight heparins tinzaparin and enoxaparin. Thromb Haemost 1999;81:22-25.

14 Samama MM, Gerotziafas GT: Comparative pharmacokinetics of LMWHs. Semin Thromb Hemost 2000;26(suppl 1):31-38.

15 Mismetti P, Laporte-Simitsidis S, Navarro C, Sié P, d'Azemar P, Necciari J, Duret JP, Gaud $\mathrm{C}$, Decousus H, Boneu B: Aging and venous thromboembolism influence the pharmacodynamics of the anti-factor $\mathrm{Xa}$ and anti-thrombin activities of a low molecular weight heparin (Nadroparin). Thromb Haemost 1998;6:11621165 . 